\title{
From the Design of Waste project to the Heartwood project: transfering concepts, methods and knowledge among university extension actions in Social Design
}

\author{
Juliana Pontes Ribeiro $^{1 \mathrm{a}}$, Adriana Tonani ${ }^{2}$, Ygor Bernardes ${ }^{3}$ e Alberto Otero ${ }^{4}$ \\ ${ }^{1}$ University FUMEC, Department: Design, Rua Cobre 200 - Belo Horizonte-MG \\ ${ }^{2}$ University FUMEC, Department: Archtecture and Urbanism, Rua Cobre 200 - Belo Horizonte-MG \\ ${ }^{3}$ University FUMEC, Department: Design, Rua Cobre 200 - Belo Horizonte-MG \\ ${ }^{4}$ University FUMEC, Department: Design, Rua Cobre 200 - Belo Horizonte-MG
}

\begin{abstract}
This article deals with the experience of sharing, expanding and developing concepts and methodologies among the university extension projects: Design of Waste and Cerne: Design, Architecture, Crafts and Art, expanding its interdisciplinary character. This reflection has the objective of documenting and discussing the technical, conceptual and practical procedures of this type of transfer of knowledge acquired between projects, in order to serve as a reference for other similar experiences. The methodology used was the one of comparative study between concepts, processes of identity construction and scope of activities of the involved projects. The results and conclusions of these analyzes provide parameters for the discussion of the expansion and continuity of university extension projects in social design, maintaining the socio-environmental commitments that govern them and taking advantage of accumulated knowledge.
\end{abstract}

Keywords. Waste Design. Heartwood. Social Design. Sustainability. Interdisciplinarity.

\section{Introduction}

In nature, the heartwood is a central, essential and enduring element of a tree trunk, a perennial part that does not rot or easily collapse. Its physical characteristics, which are concentric circular forms revealed in its cross section, resemble a fingerprint, a mark that distinguishes one human being from another. As in humans, this "digital" of each tree has its own design, its particular combination of lines, in short, a unique personality. Being an essence, a factor of distinction and a representation of resistance in nature, the word "core" - and all its symbolic charge - was chosen to give name and meaning to a university extension project that was born in 2015 , a further front of integration between academic knowledge and society.

The Heartwood: design, architecture, handicrafts and art is a development of the Waste Design extension project of FUMEC University, which was started in 2010 and remained active until July 2015, focusing on the reuse of solid waste in partnerships with poor communities, through actions of socio-environmental design and within the philosophy of sustainable design. What is proposed in this transition is to maintain the essence of the original design, Waste Design, which is the logic of reuse of solid waste through socioenvironmental design, and expand the field of action of the project to follow the maturity already achieved by the group. This expansion aims at the already existing interdisciplinarity between the four areas of design graphic, interior, fashion and product - but also actions that interconnect the design to three of its bordering fields: architecture, art and crafts. In addition, there is the intention to diversify the activities with: academic support projects for organizations, institutions and companies, aiming to reuse their solid waste by design with the surrounding communities; Actions of social awareness through technical and artistic interventions in the urban space and in architecture. It is important to maintain the actions of social technology development, product design activities and training workshops for beneficiaries and the general public.

The name Heartwood came from maintaining the essential thinking of the Waste Design project. The core is the same, the fundamental nature remains, changing its breadth both in activities and in the areas involved. However, design remains the core of interdisciplinary actions across all of its areas and a starting point for conceptualizing and generating shared social technologies. Finally, the Heartwood is a socioenvironmental innovation project through design, architecture, art and crafts.

The interdisciplinarity of the project is constituted through researches of interdisciplinary references;

\footnotetext{
a Corresponding author: ipontes@,fumec.br
} 
Collective design of products with the collaboration of the expertise of all members, who are from all areas of design, as well as architecture and art; Creation of a specific methodology for each project and training from the combined resources of these areas to the production of scientific articles reflecting on these shared experiences.

Some of the members of the Heartwood extension project also participate in the research project titled Interdisciplinary Methodologies for Social Design: proposing design and academic initiatives, which develops case studies and theoretical reflections on the performance of design with communities in a situation of social risk, in search of a current concept of Social Design. Some of the cases analyzed are extension projects in social design already carried out by participating teachers, such as ASAS, Sempre Savassi and Waste Design. These members also participated in previous research on interdisciplinary methodologies in design, as well as on the concept and production of social technology in design and crafts actions. Therefore, this project is the result of a constant integration between research and extension, generating content that will certainly be themes for future researches.
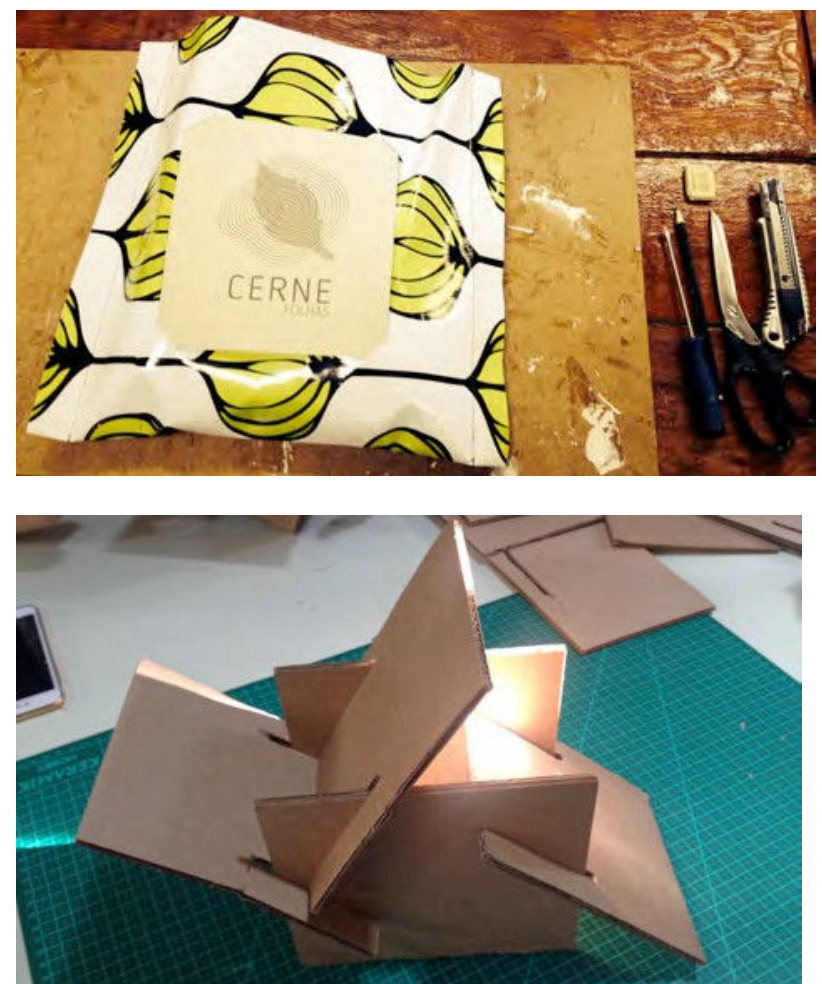

Figure 1. Workshop of modular luminaires made with recycled discarded discarded paperboard.

The initiative to expand the activities for a partnership with organizations, institutions and companies, increasing the geographic reach of the project in relation to the groups of beneficiaries, comes with the identification of an environmental need. These instances often do not have the information or human resources needed to provide an environmentally responsible destination for their waste, as well as concentrating a potential group of beneficiaries set up by their employees, their families, and the community around them, associating environmental action of the company a social character of inclusion, the feeling of belonging to a cause in solidarity with the environment and a fairer model of society.

The expected results range from artisanal products to the local reuse of waste to the reach of the creative autonomy of the beneficiaries and their ability to work professionally in groups of artisans or to solve problems of their daily life. Conceptual and educational products on the training methodology, available to the community through exhibitions, internet and presentations organized in public spaces, can also be thought of. There will necessarily be the development of social technologies and training workshops created and systematized to reapply them in other contexts. In this process, a mesasurable result was the formation of teams of teachers and university students trained for the extension action of interdisciplinary and socioenvironmental character, able to present the knowledge acquired in scientific articles with reflections on the methodological process and its results, as well as to act professionally in the field of the Social design. Finally, we aimed at the approximation between institutions, organizations, companies and the University, the increase of interest in design as a profession in all its qualifications and in its sustainable character, and the formation of an interdisciplinary understanding of design, art, architecture, and crafts for undergraduate students and the community at large.

\section{Conceptual proposal: visual signature Heartwood}

We now present the design decisions that led to the creation of the visual signature of the Heartwood brand and its derived brands, through the creative process to the solution of the design problems faced, demonstrating that the visual signature emerged after careful observations and studies about the form, counterform, graphic combinations, typography, movement, colors and alignment.

At the beginning of the process of creating the symbol, a search was made on the meaning of the word core and an iconographic survey searching for forms, textures and drawings of types of heartwoods and trees. After the research, the roughs / sketches phase was started by hand, without the initial concern about their performance in the digital environment. A critical analysis phase was necessary to evaluate the alternatives of visual structures and problems related to composition, such as balance, movement and contrast. To represent the core symbol, we concluded that abstract and simple forms, such as a perfect circle, did not result in an interesting image for the visual signature, since the mark must be strong enough to establish a link between its concept and its public, in addition to making the symbol an easily recognizable figure. Therefore, the exact and symmetrical forms of the initial options were eliminated and the focus was on the development of organic and 
more complex forms, in which it was possible to suggest a slight moiré effect, radiating from the center to the extremities of the core representation. The typography chosen was Blogger Sans, created by the designer Sergiy Tkachenko. The typographic family has four weights, its contrasts and rounded contours giving lightness and legibility to the shape. This typographic family was chosen to accompany the Heartwood symbol by creating a convenient composition with the logo, drawing no more attention than the symbol, but complementing the composition.

The orange and green colors of the symbol were chosen to refer to the colors of the Waste Design brand, original design. The way they were used is intended to give movement and distinction between the heartwood lines, reinforcing the idea of the rings of a tree.

The centralized alignment of the logo was the best option, since, being an irregular shape, it asks for a base that offers balance. In addition to the name Heartwood, the brand asks for an identification about what it refers to, so the words "design, architecture, art and crafts" are part of this visual signature, encompassing the concept of the project, after all, this is the true core of its actions, the base areas of the whole. In order to arrive at the composition of these elements several kerning experiments, alignments and weights were made.

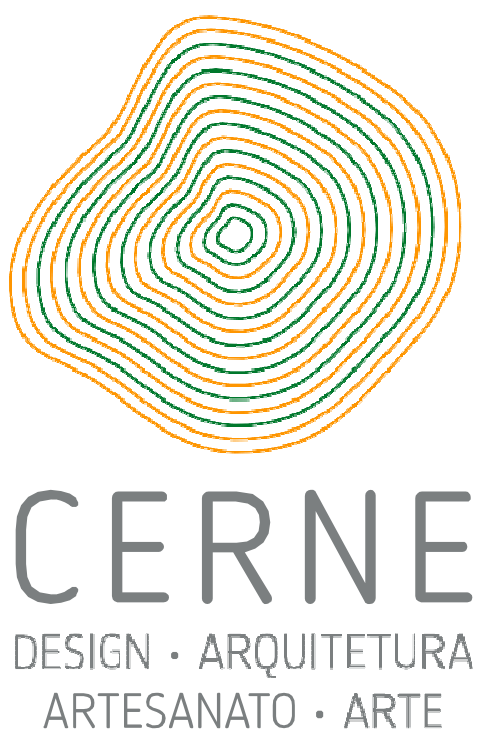

Figure 2. Visual signature of the project.

For the creation of derivative marks - Leafs, Seeds and Twigs - we use the main symbol of the brand mark superimposed on the illustrative figures, forming layers. In order to arrive at the best representation, several studies were done on how best to represent them. The first design problem encountered was the similarity between the shape of a leaf and a seed when used as silhouettes. They lose the textures and colors, leaving only the contours, which resemble in spite of the great variety of them. The solution found was to perform a search for more oval seed shapes, and an elongated silhouette of a leaf. For Heartwood Seeds the oval shape of Brazil nut perfectly fit the shape of the main symbol and provided a marked difference in relation to the shape of the leaf. After researching the forms, we arrive at the three final versions, in which we get the differences between the forms without losing the connection between their main sign, leaving them representative of both their specificities and their unity.
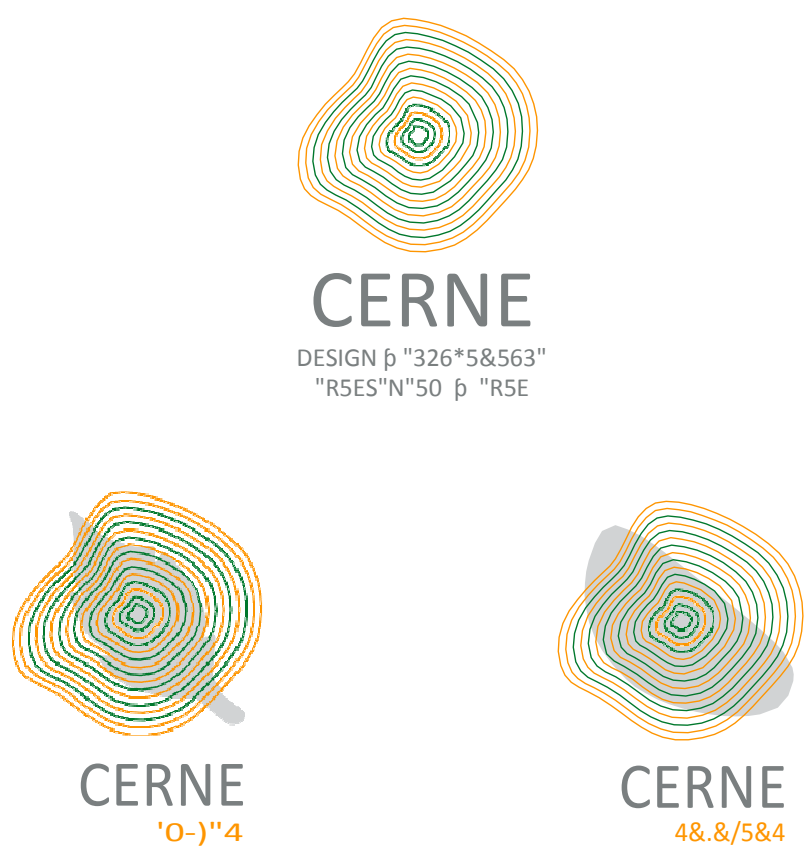
CERNE $4 \& . \& / 5 \& 4$

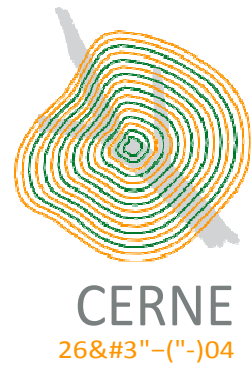

Figure 3. Deployments of the visual signature of the project Heartwood: Heartwood Leafs, Heartwood Seeds e Heartwood Twigs

The option to merge the Heartwood symbol and the derived tag symbol, forming a second core with its icons, solved the challenges faced and provided a great experience of generations of alternatives, creative methods and graphical experiments.

\section{Booklet Heartwood: Leafs, Seeds and Twigs}

The Heartwood editorial project: Leaves, Seeds and Twigs, in force since 2015, is an evolution of the initial concept of the Waste and Sustainability Rehabilitation Booklet, in progress since August 2014, whose initial objective was to follow the actions of the former Waste 
Design extension project, current Heartwood: design, architecture, handicrafts and art.

The initial intention of the booklet was to report to the academic community and the external community, mainly to the beneficiaries of the communities surrounding FUMEC University, the experiences accumulated in the Waste Design project and the themes related to sustainability present in their actions. Insofar as we understand its expanded function of communication, we resolve to embrace a larger concept of publishing products, and qualify them as Heartwood Leaves, the article book; Heartwood Seeds, the gained experiences of the Heartwood extension project; and Heartwood Twigs, the everyday tips of using recyclable materials found in various sources.

Thus, the editorial project has gained a broader intention to register and disseminate through these publications the content of these extension actions, as well as other experiences related to the theme, with the objective of materializing the access of the academic community and the groups of beneficiaries Information.

In times of digital connections and social networks, the Heartwood project also relies on a communication tool for web, in a blog format, which plays the role of disseminating on a large scale our ideas, experiences, methodologies and actions. Therefore, the printed product is more a documentation option, to create an affinity, handling and registration object that also meets the need to read on paper and to provoke the physical contact experiences of interaction with the printed object and its sensory qualities.

\subsection{Graphic formats and content equivalence}

The information is systematized with three different types of content. The first, which has the format of an article book, will contain the theoretical reflections raised by the waste design, sustainability and socioenvironmental actions of the Heartwood extension project. For this content, we chose the name Heartwood Leafs, associating the concept of the ideas to be presented in articles of the team of students and teachers of the project, in a binding format with several pages, to the idea of the different leaves of trees to be compensated by the actions of our projects.

The second format concerns the social technologies developed in the projects and will be published in a "step by step" format as a simplified guide to actions to be reapplied in other project situations or in people's daily lives. The name chosen for this editorial product is Cerne Seeds, since the ideas presented will serve as small seeds of innovations in other experiences, from our publication.

The third is a collection of reuse, recycling and waste design tips found in everyday community and other experiences published on blogs and websites in general. The name Heartwood Twigs refers to these technologies and strategies developed in the daily life of the people that serve the goal of problem solving, survival tools or free appropriation of structuring thoughts of general purpose design objects.

\subsection{Objectives of the development of the booklet}

The Heartwood booklet project and its related products have as main objectives the community, firstly, transfering to then the knowledge already validated and acquired in other extension projects, creating a critical view of what has already been consolidated in previous experiences. Another objective is the approximation between the theoretical-scientific knowledge and the pragmatic of the people of the community, in such a way that it becomes a vehicle for reapplication of the social technologies acquired in the University-Community relationship.

With respect to the academic community, the book's development objectives are: the generation of an innovative and efficient editorial design for the clear and objective transmission of its information and the preparation of scholarship students for the selection and organization of the contents to be published and its organization in graphic products and subsequent printing and dissemination.

All the editions, which began annually, intend to reassess the type of production resulting from socioenvironmental actions already consolidated in a type of editorial format that includes the theoretical-critical reflection on these practices, as well as infographic and illustrated syntheses of the practical subjects of daily life.

\subsection{Process of creating the graphic materials}

\subsubsection{Phase 1: methodology and concept}

At the first meetings of the project, a briefing was held. Briefly, the guidelines dealt with the content, which should be a kind of service, by presenting information that is direct and important to the daily lives of people (academic and society in general). And, along with this service, take the opportunity to show, with prominence, the new visual signature of the Heartwood and its three thematic areas. Another direction was the conscious and sustainable use of paper, which is one of the innumerable ways of preserving the environment. With this information, it was then started for the elaboration of the pieces. The methodology adopted for the creative process was divided into three distinct but not watertight phases: concept creation, content definition and part development. It is noteworthy that the three phases were based on research.

The use of the methodology discussed above helps to think and plan better the strategy to be adopted in the elaboration of graphic materials and, consequently, facilitates the progress of the creative process. According to Fuentes (2009, pp. 14-15), the use of methodology is important because "it increases the knowledge of things and gives greater support to the creative act, which 
allows to broaden the points of view on a certain problem, increasing the Their knowledge and facilitating a global creative perspective until its resolution. "

With the analysis of the briefing, and after reflections, discussions and research, the concept "The question of sustainability in your hands" was reached. This concept has two proposals that are aligned with the Heartwood: to show that, in addition to being responsible for sustainable attitudes and actions, you will have useful and practical information and guidance to consult when and where you want.

\subsubsection{Phase 2: The content}

The Heartwood booklet has three well-defined thematic areas with different communication objectives. Thus, it was decided to present, in this first moment, three "step by step" scripts, three "tips" and four "academic articles", referring respectively to the Heartwood Seed, Twigs and Leafs.

In step-by-step, the choice of PET Wire creation workshops; Of Spiral and Binding; And Warranty Machine was made due to the ease of reapplication of these technologies in diverse situations and contexts. In such cases, both materials and handling and procedures are accessible economically and in terms of learning and acquiring skills. In this item, it is essential to maintain themes and scripts that are easy to understand but also feasible in terms of graphic representation, always aiming at processes of visual learning by illustrated infographics.

The tips on reuse of materials - especially e-waste, the discard of cooking oil and the reuse of paper address current issues of broad interest in everyday life. As they are specific information, it is fundamental the care with the credibility of the sources and the relevance of the subjects. Offering a selection of more than one search source to the contents of each tab is also a concern, precisely to offer different parameters for the reader.

The academic articles unfold the reflections and discussions about the actions in social design and its primordial questions. Generally, they are produced by the teachers and students of the projects involved, as well as guests who dominate the areas and themes involved in the booklet. As of the second edition, a central theme will guide the choices of all three thematic areas of the booklet, providing more precise terms for thematic specifications.

\subsubsection{Phase 3: Graphic design and layout}

Based on the information described in the briefing and after researching several visual references, the format of the graphic materials was defined: in the Heartwood Seeds - poster, in the Twigs - technical cards; and in the Leafs - sheets with articles. Thinking that these future products are used at different times, due to the content, we chose to create three different graphics formats, but with graphic unit. With the guidance on the concept, content and relationship of the format $\mathrm{x}$ function of the materials, we set out to develop the layout of the three pieces.

The infographics were the definite style to be worked on the poster. The infographics have the purpose of facilitating the presentation of an information, making it clearer precisely because the explanation of the data and its relations is done by visual syntheses, displaying in a more rapid and practical way the contents. Thus, the creation of the illustrations, which would be simple and easy to associate with the real elements, was started, conveying the idea of step-by-step and the very purpose of the workshops (which is to show that the process is manual, easy and can be executed by all). Moraes (2013, p.20), in Infography - History and Design, summarizes how the infographic creation process is performed:

[...] an infographic must be based on credibility - its production supposes research work, which is greater than a search for references (common in the production of illustrations): one has to get up and calculate information, size it according to the objectives of the work; Translate them as much as possible into nonverbal language and relate them clearly to the text, which can also be produced by the author of the infographic.

It is worth emphasizing that the text should be clear, objective and helpful, since the illustrations "should speak for themselves". Following the concept of the material, we opted for the handwritten typography called Bromine, of free use. After researching the visual references for the poster, a model with double-sided printing, $38.5 \mathrm{~cm} \times 68 \mathrm{~cm}, 1 / 1$ color, Color Plus paper with a weight of $90 \mathrm{~g}$ and 5 folds. At the front would be applied the visual signature, with emphasis and, on the back, the three infographics.

With the proposal to gather the materials at the time of delivery, the idea came up to make the poster an envelope for the other materials. Thus, it would not be necessary to create and produce a fourth piece to integrate them. This solution, in addition to reducing costs, contributes to the rational use of paper.

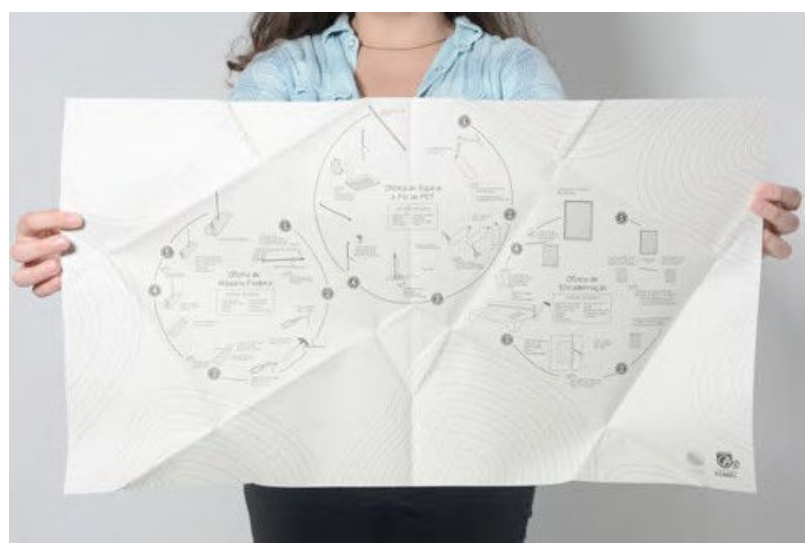



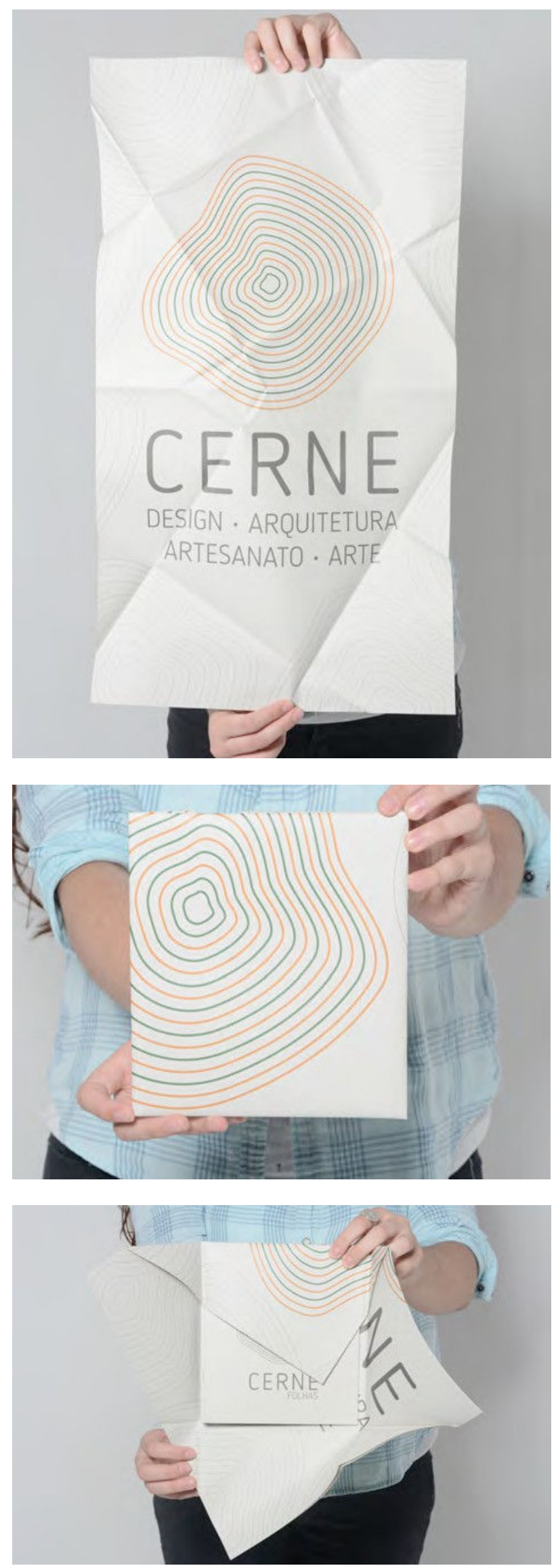

Figure 4. In the vertical sequence: poster with infographic of the pass-to-step of developed technologies; Open poster verse; The closed primer, enveloped by the poster; And the procedure of opening the graphic part.
For the cards, a brief content was chosen that would approach the contextualization of a certain residue, with the presentation of the consumption data of the products that generate this residue, the possible consequences of its incorrect disposal, tips of reutilization and how to discard.

The text was developed based on research on the topics covered. Based on the consumption and disposal data, infographics were created with more playful illustrations. Two types were used in this material. Bromine was applied in the infographic and titles, highlighting the information and collaborating to break the formality of the piece. Sansation Light, which is a sans serif free font, bears a certain resemblance to that used in the Heartwood brand, which contributes to the identity of the pieces.

The format defined was $17 \mathrm{~cm} \times 19 \mathrm{~cm}$, on Color Plus paper, with a weight of $240 \mathrm{~g}$. The two-column grid gave the piece an adequate reading movement and a good breathing area. With only one color, the piece has front and back, and in the front, would be applied, particulary, the mark of the Twigs and, on the back, the explanatory content.

During the process of elaboration of the material came the idea of making it a collectible piece. To do this, a hole was marked in the upper left corner, which would be highlighted during the production process, so people could tie the chips with a string, for example, and store them together, mounting their collection.

The purpose of the booklet, already mentioned, was to gather academic articles. This orientation made the graphic design of this material a little more formal, in view of its function. With a format of $17 \mathrm{~cm} \mathrm{x} 19 \mathrm{~cm}, 24$ pages in one color, in Color Plus paper, with a weight of $180 \mathrm{~g}$ for the cover, and $50 \mathrm{~g}$ newspaper, for the core, the Sansation Light typography was applied to generate identity and unity between the Materials. The grid used was the six-column grid. In the presentation pages, it was decided to leave the text running, because there was no prominent information or quotes. This did not occur in the pages of the articles, in which there was displacement of the text due to complementary information. To break the highly formal character of the publication and generate movement, the stylized plot of the visual signature was applied on some pages.

As can be seen, the presented parts have different characteristics and functions. The challenge was to generate unity among them, as well as to make rational use of paper, since their inconsequential consumption causes numerous damages to the environment. Therefore, in addition to the unit obtained with the graphic elements described, the choice of roles contributed to the identity of these products, in addition to having the FSC forest certification seal, which marks the objective of the extension project, which is the environmental awareness.

It is understood that, when using alignments and graphic standards that are related to formats, types of paper, typography, colors and aesthetic resources, while maintaining the characteristics of the product itself, unity and identity can be achieved. In this specific case, there 
was still another solution, the poster as envelope, which would gather and organize the graphic products for delivery, generating, besides saving paper and financial resources, the unity between them.

\section{Conclusion}

Finally, what we conclude from this experience of transition between projects is that the intention to take a step forward towards expanding the scope and scope of a project means to step up a commitment to the initial conceptual and ideological foundations. It is not possible to expand the vision and scope of a university extension proposal without also intensifying the theoretical bases and the pacts with a more just and environmentally more consistent society.

In this sense, it is perceived that it is not only a broadening of horizons of action, but it is necessary to generate transition processes, which begin in the construction of identity, intensifying the conceptual parameters of the proposal, and go through the structuring of new actions and new goals. It becomes a process of awareness of the scale and implications of new perspectives. A maturing attitude toward new responsibilities and commitments to society and the shared production of knowledge.

\section{References}

DESIGN DE RESÍDUOS. Available in: https://designresiduofumec.wordpress.com. Accessed June 2015.

FUENTES, Rodolfo. A prática do design gráfico: uma metodologia criativa. São Paulo: Rosari, 2006.

MORAES, Ary. Infografia: história e projeto. São Paulo: Blucher, 2013.

O QUE É UM INFOGRÁFICO? [2014]. Available in: $<$ http://www.oficinadanet.com.br/post/12736-o-que-eum-infografico $>$. Accessed June 2015

PANIZZA, F. J. Metodologia e processo criativo em projetos de comunicação visual. 2004, 254 p. Dissertation (Master in Communication Sciences) School of Communication and Arts, University of São Paulo, São Paulo.

PÉON, Maria Luísa. Sistemas de Identidade Visual: um guia sucinto para pesquisar, criar, avaliar e especificar identidades visuais. Rio de Janeiro: Editora 2ab, 2000.

PEREZ, Clotilde. Signos da marca: expressividade e sensorialidade. São Paulo: Pioneira Thomson Learning, 2004.

RECICLAGEM: impressão sustentável avança em jornais. [2010]. Available in: $<$ http://observatoriodaimprensa.com.br/monitor-da- imprensa/folha-de-s-paulo-39493/>. Accessed June 2015.

SILVA, R.; GRUSZYNSKI, C.A. O projeto gráfico de periódicos científicos: uma contribuição aos roteiros de avaliação. Em questão. Porto Alegre, v. 11, n.2, jul./dez. 2005. Available in: $<$ http://seer.ufrgs.br/EmQuestao/article/viewFile/123/81 $>$ Accessed July 2015.

TONDREAU, B. Criar Grids, 100 Fundamentos de Layout. São Paulo: Editora Blücher, 2009.

WHEELER, Alina. Design de identidade da marca: um guia completo para a criação, construção e manutenção de marcas. Porto Alegre: Bookman, 2008. 